\title{
Strong binding at the gold (Au) boron carbide interface
}

Elena Echeverría, elena-maria-echeverria-mora@ huskers.unl.edu

Department of Physics and Astronomy, University of Nebraska-Lincoln 855 North 16th Street, Lincoln, NE 68588-0299, USA

Bin Dong, bindong@my.unt.edu

Department of Chemistry, University of North Texas

1155 Union Circle \#305070, Denton, TX 76203, USA

Aiyun Liu, liuaiyun2015@gmail.com

Department of Physics and Astronomy, University of Nebraska-Lincoln 855 North 16th Street, Lincoln, NE 68588-0299, USA

Department of Physics, Shanghai Normal University

100 Gin Lin Road, Shanghai 200234, China

Ethiyal R. Wilson, ethiwilson@yahoo.com

Department of Physics and Astronomy, University of Nebraska-Lincoln

855 North 16th Street, Lincoln, NE 68588-0299, USA

George Peterson, george.peterson@ @uskers.unl.edu

Department of Mechanical and Materials Engineering, University of Nebraska-Lincoln

Walter Scott Engineering Center, Lincoln, NE 68583-0857, USA

Michael Nastasi, mnastasi2@unl.edu

Department of Mechanical and Materials Engineering, University of Nebraska-Lincoln, Walter Scott Engineering Center, Lincoln, NE 68583-0857, USA

Peter A. Dowben, pdowben1@unl.edu

Department of Physics and Astronomy, University of Nebraska-Lincoln

855 North 16th Street, Lincoln, NE 68588-0299, USA

\section{Corresponding Author:}

Jeffry A. Kelber, Jeffry.Kelber@unt.edu

Department of Chemistry, University of North Texas

1155 Union Circle \#305070, Denton, TX 76203, USA 


\title{
Strong binding at the gold (Au) boron carbide interface
}

\section{Elena Echeverría, ${ }^{\mathrm{a}}$ Bin Dong, ${ }^{\mathrm{b}}$ Aiyun Liu, ${ }^{\mathrm{a}, \mathrm{c}}$ Ethiyal R. Wilson, ${ }^{\mathrm{a}}$ George Peterson, ${ }^{\mathrm{d}}$ Michael Nastasi, ${ }^{\mathrm{d}}$ Peter A. Dowben, ${ }^{\mathrm{a}}$ and Jeffry A. Kelber ${ }^{\mathrm{b}}{ }^{*}$}

${ }^{a}$ Department of Physics and Astronomy, Nebraska Center for Nanostructures and Materials, University of Nebraska-Lincoln, 855 North 16th Street, Lincoln, NE 68588-0299, USA

${ }^{\mathrm{b}}$ Department of Chemistry, University of North Texas, 1155 Union Circle \#305070, Denton, TX 76203, USA

c Department of Physics, Shanghai Normal University, 100 Gin Lin Road, Shanghai 200234, China

${ }^{\mathrm{d}}$ Department of Mechanical and Materials Engineering, University of Nebraska-Lincoln, Lincoln, NE 68583-0857, USA

\begin{abstract}
We have investigated the interaction of gold $(\mathrm{Au})$ with the semiconductor boron carbide through X-ray photoemission. Hydrogenated semiconducting boron carbide films, deposited by plasma enhanced chemical vapor deposition (PECVD) of closo-1,7-dicarbadodecaborane (metacarborane, $m$ - $\mathrm{B}_{10} \mathrm{C}_{2} \mathrm{H}_{12}$ ), show a shift in the binding energies of the core level photoemission features when gold is deposited on the surface. The shifting of the B 1s level is smaller than for the $\mathrm{C} 1 \mathrm{~s}$ level and the non-uniform nature of the shifts indicates a strong, complex and reversible Au chemical interaction with the surface, particularly with the $\mathrm{C}$ sites. Capacitance versus voltage, $\mathrm{C}(\mathrm{V})$ and current versus voltage, $\mathrm{I}(\mathrm{V})$, results for the film deposited on p-type $\mathrm{Si}(100)$ yield a carrier scattering time of $50 \mathrm{~ns}$, significantly smaller than the $35 \mu$ s for the PECVD orthocarborane boron carbide films.
\end{abstract}




\section{Keywords}

Boron Carbide; metal contact; electrical properties; carrier lifetimes

*kelber@unt.edu; +1-940-565-3265 


\section{Introduction}

Semiconductor boron carbides have been shown to be suitable for semiconducting devices [1-21] and solid state neutron detection [11-23]. Essential to any semiconductor device is the metal contact and the chemical interactions or band bending that may occur at the metal/semiconductor interface, so increasingly there has been investigation of the interface of various boron carbides to various metals [24-27]. Understanding the metal contacts on the surface of these semiconductors presents a number of important challenges. Such interface characteristics could lead to either rectifying or non-rectifying junctions $[28,29]$, affecting device functionality. While semiconducting boron carbides are generally p-type, in the absence of transition metal doping [1,4-6], hydrogenated semiconducting boron carbides made by the plasma enhanced chemical vapor deposition (PECVD) from metacarborane (the closo-1,7dicarbadodecaborane isomer of the icosahedral closo-carboranes, $\mathrm{C}_{2} \mathrm{~B}_{10} \mathrm{H}_{12}$ ) are generally $\mathrm{n}$-type $[11,13,30]$. As such, a fairly unreactive large work function metal contact, such as Au (with a work function in the range of 5.3 to $5.5 \mathrm{eV}$ [31-33]) or Pt (with a work function in the range of 5.6 to $5.9 \mathrm{eV}[33,34])$, would be expected to form a Schottky barrier contact. Low work function metals have attracted much attention, but are often seen to be quite reactive at the interface with boron carbide [24]. A less reactive metal, with high work function, is an important juxtaposition, and may afford insight as to whether the formation of Schottky barrier contacts with PECVD hydrogenated semiconducting boron carbide is facile. Schottky barrier contacts, while increasing the complexity of a heterojunction diode device's performance, and while likely leading to increases in device capacitance, have the potential advantage of reducing leakage and some parasitic currents that would hamper pulse counting in neutron detection. The investigation of the interaction of gold with hydrogenated semiconducting boron carbide is therefore a natural 
extension of efforts to understand how to optimize the contacts to PECVD boron carbide devices.

\section{Experimental}

The boron carbide film was formed by plasma enhanced chemical vapor deposition (PECVD), as described in prior work [27], using closo-1,7-dicarbadodecaborane (metacarborane, m- $\mathrm{B}_{10} \mathrm{C}_{2} \mathrm{H}_{12}$ ) in a 20 mTorr Ar inductively coupled plasma $(20 \mathrm{~W}$ ), and deposited on atomically clean p-type $\mathrm{Si}(100)$. This isomer of the icosahedral closo-carboranes, $\mathrm{C}_{2} \mathrm{~B}_{10} \mathrm{H}_{12}$, has been successfully used as a PECVD source compound for forming a hydrogenated n-type semiconducting boron carbide $[11,13,17,30], \mathrm{B}_{10} \mathrm{C}_{2} \mathrm{H}_{12-\mathrm{x}}$, thus making the fabrication of an all boron carbide semiconductor diode device possible [11,13]. During PECVD, the partial vapor pressure of metacarborane in the PECVD chamber was $\sim 1$ mTorr, created by sublimation through annealing the source compound and gas lines to $70-80^{\circ} \mathrm{C}$. The partial vapor pressure of metacarborane was controlled by a mass flow controller at $5 \mathrm{sccm}$ (standard cubic centimeters per minute).

X-ray photoemission spectroscopy (XPS) was used to characterize the Au interface with semiconducting boron carbide. Experiments were carried out in an ultrahigh vacuum (UHV) system, to prevent impurity scattering events. The XPS spectra were acquired with a dual anode X-ray lamp and a hemispherical angle resolved electron energy analyzer (detector). The X-ray source used the $\mathrm{Mg}-\mathrm{K} \alpha$ line at $1253.6 \mathrm{eV}$, with data taken at normal emission. Data were acquired with the analyzer in constant pass energy mode $(50 \mathrm{eV})$. Core level spectra were analyzed using CASAXPS [35], and a Shirley background [36] was used for all spectra. 
Prior to Au deposition, the film was cleaned by $\mathrm{Ar}^{+}$bombardment at $\sim 9.5 \times 10^{-5}$ Torr at $1.0 \mathrm{kV}$ for $15 \mathrm{~min}$. To maximize the uniformity of the reduced surface layer, the sample was rotated $\pm 40^{\circ}$ off normal, with respect to the incident ion beam. Following the initial sputter cleaning of the sample surface, no oxygen was evident in XPS (i.e. no O(1s) core level photoemission peak above the background noise). Gold(Au) was deposited via thermal evaporation from a tungsten(W) filament at a pressure of $10^{-7}$ Torr. Different Au coverages ranging from $4 \AA$ to $21 \AA$ average thickness, as determined by XPS, were investigated. After deposition of $\mathrm{Au}$ on the PECVD hydrogenated boron carbide film, the sample was transferred to the photoemission chamber, in vacuo, without exposure to ambient conditions. The core level $\mathrm{B}(1 \mathrm{~s}), \mathrm{C}(1 \mathrm{~s})$ and $\mathrm{Au}(4 \mathrm{f})$ binding energies were obtained from the XPS spectra before and after each Au deposition experiment.

$\mathrm{Ar}^{+}$bombardment was also used to remove deposited $\mathrm{Au}$ from the boron carbide surface to determine the reversibility of Au-boron carbide surface interactions. During the sputtering process, the same Ar pressure and beam voltage conditions were used as for initial surface cleaning. Different Ar ion sputtering times, however, running from $15 \mathrm{~min}$ to 1 hour, were selected in order to eliminate more Au layers.

The capacitance versus voltage, $\mathrm{C}(\mathrm{V})$ and current versus voltage, $\mathrm{I}(\mathrm{V})$, measurements were used to extract estimates of the carrier diffusion lifetime, as was done elsewhere [37,38]. The procedure followed here is as in [37]. Corresponding transistor and Hall measurements are certainly indicated, but because of the high resistivity of the PECVD hydrogenated semiconducting boron carbide $\left(10^{10}\right.$ to $\left.10^{12} \mathrm{Ohm} \cdot \mathrm{cm}\right)$, these supporting measurements are beyond the scope of this work. 


\section{Results and Discussion}

\section{III.1 Evidence of Strong Gold-Boron Carbide Interactions}

Fig. 1 shows the evolution of $\mathrm{B}(1 \mathrm{~s})$, and $\mathrm{C}(1 \mathrm{~s})$ spectra with deposition and subsequent removal of a Au overlayer. The measured XPS binding energies for boron and carbon are summarized in table 1 . Some oxygen was observed before sample cleaning, but its intensity decreased after $\mathrm{Ar}^{+}$bombardment (and its concentration did not change appreciably with $\mathrm{Au}$ deposition; therefore it is not shown in this work). Spectra a and e in Fig. 1 refer to the sample after cleaning. As expected no oxygen bonds are present. The B(1s) spectra are deconvoluted into two peaks: one at low binding energy corresponding to the B-B bond, and the second one at higher binding energy representing the B-C bond. For the samples $\mathrm{Ar}^{+}$ion sputtered free of contamination, values for binding energies representing these peaks are in good agreement with previous results [24-27,39-40]. Unlike in other work on orthocaroborane-derived films, there is a single $\mathrm{C}(1 \mathrm{~s})$ core level feature as there is no $\mathrm{C}-\mathrm{C}$ carbene bond in the metacarborane icosahedra, making core level shifts far easier to identify. The main $\mathrm{C}(1 \mathrm{~s})$ core level peak in these spectra is attributed to $\mathrm{C}-\mathrm{B}$ bonding environments.

As $\mathrm{Au}$ is deposited on the sample, the B(1s) core level XPS spectra exhibit a small feature at higher binding energy, 191.5 to $192.1 \mathrm{eV}$, while the main B(1s) core level XPS feature is seen to shift about $0.5 \mathrm{eV}$ to higher binding energy (Fig. 1b, and 1c and table 1). The shift is substantially more dramatic for the $\mathrm{C}(1 \mathrm{~s})$ core level.

The C(1s) XPS spectra show a gradual increase in C(1s) binding energy and the addition of a satellite feature near $289 \mathrm{eV}$ binding energy (Fig. 1e-g and Table 1). This growth of a significant satellite feature, accompanied by the large increase in binding energy of the main 
$\mathrm{C}(1 \mathrm{~s})$ peak with increasing of $\mathrm{Au}$ overlayer coverages, indicates that carbon reacts with $\mathrm{Au}$ forming $\mathrm{C}-\mathrm{Au}$ bonds at the semiconductor-metal interface. This increase in core level binding energy is significantly larger than observed for the $\mathrm{B}(1 \mathrm{~s})$ spectra, indicating that this effect cannot be ascribed to simple Au-induced band bending. This also suggests that Au-C interactions are stronger than Au-B interactions. As expected, the high binding energy $\mathrm{B}(1 \mathrm{~s})$ and $\mathrm{C}(1 \mathrm{~s})$ features disappear once $\mathrm{Au}$ is completely removed with $\mathrm{Ar}^{+}$bombardment (Fig. 1d, and Fig. 1h). The core level energies of the main peaks are also largely restored.

Fig. 2 plots the evolution of the $\mathrm{B}(1 \mathrm{~s})$ core level binding energy as the gold overlayer is added and then removed. The B(1s) core level shifts to higher binding energies as Au coverage increases (Fig. 2, * black stars), but is reversible upon removal of the gold overlayer (Fig. 2, red triangles). This indicates that if band bending is induced at the metal/semiconductor interface, the shift is to higher binding energies. This cannot be a photovoltaic charging effect, as the binding energy increases as the surface is metallized, which would lead to a decrease in binding energy if there was significant suppression of photovoltaic charging.

While such an increase in binding energy has been seen with the addition of a copper overlayer on various boron carbides [24-27], there are some subtle differences. Metacarborane (closo-1,7-dicarbadodecaborane) is unusual in that it is generally regarded as a n-type material $[11,13,17,30]$. As gold has a large work function (in the range of 5.3 to $5.5 \mathrm{eV}$ [31-33], as noted above), this means that Schottky barrier formation should be favored as it is for many semiconductors, and the apparent binding energy should decrease with increasing gold coverage. Increasing binding energy indicates strong interfacial interaction where gold exchanges charge with the semiconductor through the $\mathrm{C}$-Au bonds. While gold is generally considered unreactive, interfaces with gold can be quite complex. Electron charge abstraction from graphene, at the gold 
interface, is known and predicted [41-44] and boron carbide is more reactive than graphene. A sputtered semiconducting boron carbide, as is the case here, may have a number of dangling bonds and may be even more reactive than a boron carbide whose surface has not been damaged by $\mathrm{Ar}^{+}$ion sputtering.

Previous results reported a metal oxide layer in the case of $\mathrm{Cr}$, Ti and Al metals, which could lead to increased Schottky barrier heights [24]. Here, no metal oxide layers were found, and no oxygen diffusion from the bulk was observed. As a result, low device resistance at the metal-semiconductor interface is predicted. This study was limited to thin layers of $\mathrm{Au}$, but no evidence of Au diffusion into the bulk was found. The gold adlayer could be almost completely removed with modest $\mathrm{Ar}^{+}$ion sputtering. If gold diffused into the bulk of the PECVD hydrogenated semiconducting boron carbide, then a persistent gold signal would be present, even after significant $\mathrm{Ar}^{+}$sputtering, and the facile removal of the $\mathrm{Au}$ overlayer would be hindered. Furthermore, we find that the concentration of oxygen at the surface and bulk can be minimized.

\section{III.2 Electrical measurements}

To demonstrate that n-type PECVD hydrogenate semiconducting boron carbide is formed from the decomposition of metacarborane $\left(m-\mathrm{B}_{10} \mathrm{C}_{2} \mathrm{H}_{12}\right)$, heterojunction diodes were fabricated with p-type silicon, and electrical measurements were taken. Figure 3 shows the current-voltage, $\mathrm{I}(\mathrm{V})$ and capacitance-voltage, $\mathrm{C}(\mathrm{V})$ curves for the resulting diodes. As expected, $\mathrm{m}-\mathrm{B}_{10} \mathrm{C}_{2} \mathrm{H}_{12}$ makes an excellent $p$ - $n$ diode when deposited on $p$-type silicon, showing a very small leakage current in the reverse bias region, and less than $1 \mathrm{nA}$ in the region of zero bias. The very large turn-on voltage in forward bias is similar to, but not quite as extreme, as that seen for the all boron carbide heterojunction diodes [30], that included an n-type boron carbide. The I(V) and 
$\mathrm{C}(\mathrm{V})$ data provide no indication of any Schottky barrier formation. On the other hand, the capacitance changes significantly with the frequency (Fig. 3b), indicating that there are some charge carriers that can no longer respond to the perturbation signal as the frequency increases.

The carrier lifetime value varies the height and slope of the small forward bias rise in the C(V) curve. We have modeled the device capacitance, as seen in Figure 4, and found a good fit using a carrier lifetime of about $50 \mathrm{~ns}$. This would be a very short lifetime, roughly $10^{3}$ shorter than the $35 \mu$ s indicated by $\mathrm{I}(\mathrm{V})$ and $\mathrm{C}(\mathrm{V})$ data for the PECVD orthocarborane boron carbide film on silicon [39], and far smaller than suggested by the findings of Bao et al. [38] for sputterdeposited boron carbide films which indicated carrier lifetimes of 0.91 to $0.98 \mathrm{~ms}$.

\section{Summary}

X-ray photoemission spectroscopy was used to identify the core level binding energy shifts seen with $\mathrm{Au}$ adlayer film on a hydrogenated semiconducting boron carbide film formed from the plasma enhanced chemical vapor deposition (PECVD) of boron carbide from closo-1,7dicarbadodecaborane (metacarborane, $\left.m-\mathrm{B}_{10} \mathrm{C}_{2} \mathrm{H}_{12}\right)$. The characteristic $\mathrm{B}(1 \mathrm{~s})$ and $\mathrm{C}(1 \mathrm{~s})$ core levels of boron carbide were observed to increase, as the Au the gold overlayer concentration increased. This was especially significant for the C (1s) core level, suggesting gold interaction with the carbon was significant. The absence of the typical signatures of Schottky barrier formation, yet the strong interactions evident in the core level shifts and addition of a core level satellite features suggests that at least some extrinsic interface doping of the boron carbide by gold or formation of a metal-induced gap state at the interface. The facile manner in which gold can be removed from this boron carbide surface does suggest that diffusion of gold into the boron carbide surface region does not occur at room temperature. 


\section{Acknowledgements}

This work was supported by the Defense Threat Reduction Agency (Grant No. HDTRA1-14-10041), the National Aeronautics and Space Administration through grant 13-EPSCoR-0012, and the National Science Foundation through the Nebraska Materials Research Science and Engineering Center (Grant No. DMR-1420645). ERW was supported by Nebraska Public Power District through the Nebraska Center for Energy Sciences Research and an

SRC research fellowship associated with by C-SPIN, part of STARnet, a Semiconductor Research Corporation program sponsored by MARCO and DARPA (SRC 2381.002 and 2381.003). AL was supported by the China Scholarship Council (No. 201408310002). GP was supported by the Office of Research and Economic Development at the University of Nebraska-Lincoln. 


\section{References}

[1] S. Hwang, K. Yang, P.A. Dowben, A. A. Ahmad, N. J. Ianno, J. Z. Li, J. Y. Lin, H. X. Jiang, D. N. McIlroy, Fabrication of n-type nickel doped $\mathrm{B}_{5} \mathrm{C}_{1+\delta}$ homojunction and heterojunction diodes, Appl. Phys. Lett. 70 (1997) 1028.

[2] S. Hwang, D. Byun, N. J. Ianno, P.A. Dowben, H. R. Kim, Fabrication of boron-carbide/boron heterojunction devices, Appl. Phys. Lett. 68 (1996) 1495.

[3] D. Byun, B. R. Spady, N. J. Ianno, P.A. Dowben, Comparison of different chemical vapor deposition methodologies for the fabrication of heterojunction boron-carbide diodes, Nanostruct. Mater. 5 (1995) 465.

[4] S. Hwang, N. B. Remmes, P. A. Dowben, D. N. McIlroy, Nickel doping of boron carbide grown by plasma enhanced chemical vapor deposition, J. Vac. Sci. Technol., B 14 (1996) 2957.

[5] S. Hwang, N. Remmes, P. A. Dowben, D. N. McIlroy, Nickel Doping of Boron Carbide and Corresponding Fermi Level Shifts, J. Vac. Sci. Technol. B 15 (1997) 854.

[6] L. Carlson, D. Lagraffe, S. Balaz, A. Ignatove, Y. B. Losovyj, J. Choi, P. A. Dowben, J. I. Brand, Doping of boron carbides with cobalt, using cobaltocene, Appl. Phys. A 89 (2007) 195.

[7] P.A. Dowben, A. Y. Ignatov, J. Liu, R. Skomski, The local environment of Co in $\mathrm{B}_{5} \mathrm{CH}_{\mathrm{x}}$, J. Appl. Phys. 103 (2008) 07D125.

[8] S. Balaz, D.I. Dimov, N.M. Boag, K. Nelson, B. Montag, J.I. Brand, P.A. Dowben, The electronic structure of 1,2- $\mathrm{PCB}_{10} \mathrm{H}_{11}$ molecular films: a precursor to a novel semiconductor, Appl. Phys. A 84 (2006) 149.

[9] J. Liu, G. Luo, W. Mei, O. Kizilkaya, E.D. Shepherd, J.I. Brand, P.A. Dowben, The local structure of transition metal doped semiconducting boron carbides, J. Phys. D Appl. Phys. 43 (2010) 085403.

[10] E. Echeverria, F.L. Pasquale, J.A. Colón-Santana, L. Zhang, R. James, A. Sokolov, J.A. Kelber and P.A. Dowben, Significant magneto-resistive effects in boron carbide thin films, Mat. Lett. 110 (2013) 20.

[11] G. Peterson, Q. Su, Y. Wang, P. Dowben, M. Nastasi, Improved p-n hetero-junction device performance induced by irradiation in amorphous boron carbide films, Mat. Sci. Eng. B 202 (2015) 25.

[12] A. N. Caruso, P. A. Dowben, S. Balkir, N. Schemm, K. Osberg, R. W. Fairchild, O. B. Flores, S. Balaz, A. D. Harken, B. W. Robertson, J. I. Brand, The all boron carbide diode neutron detector: Comparison with theory, Mater. Sci. Eng. B 135 (2006) 129. 
[13] B. W. Robertson, S. Adenwalla, A. Harken, P. Welsch, J. I. Brand, P. A. Dowben, J .P. Claassen, A class of boron-rich solid-state neutron detectors, Appl. Phys. Lett. 80 (2002) 3644.

[14] A. N. Caruso, R. B. Billa, S. Balaz, J. I. Brand, P. A. Dowben, The heteroisomeric diode, J. Phys. Condens. Matter 16 (2004) L139.

[15] B.W. Robertson, S. Adenwalla, A. Harken, P. Welsch, J. I Brand, J.P. Claassen, N.M. Boag, P.A. Dowben, Advances in neutron scattering instrumentation, Proc. SPIE 4785 (2002) 226-233.

[16] S. Adenwalla, R. Billa, J. I. Brand, E. Day, M. J. Diaz, A. Harken, A. McMullen-Gunn, R. Padmanabhan, B.W. Robertson, Proc. Penetrating radiation system and applications V, Proc. SPIE 5199 (2004) 70-74.

[17] K. Osberg, N. Schemm, S. Balkir, J. I. Brand, M. S Hallbeck, P.A. Dowben, M.W. Hoffman, A handheld neutron-detection sensor system utilizing a new class of boron carbide diode, IEEE Sens. J. 6 (2006) 1531-1538.

[18] K. Osberg, N. Schemm, S. Balkir, J. I. Brand, M. S. Hallbeck, P.A. Dowben, A hand-held neutron detector sensor system, IEEE Int. Symp. Circ. S (2006) 1179.

[19] E. Day, M. J. Diaz, S. Adenwalla, Effect of bias on neutron detection in thin semiconducting boron carbide films, J. Phys. D: Appl. Phys. 39 (2006) 2920.

[20] N. Hong, J. Mullins, K. Foreman, S. Adenwalla, Boron carbide based solid state neutron detectors: the effects of bias and time constant on detection efficiency, J. Phys. D: Appl. Phys. 43 (2010) 275101.

[21] N. Hong, L. Crow, S. Adenwalla, Time-of-flight neutron detection using PECVD grown boron carbide diode detector, Nuc. Intrumen. Methods Phys. Res. A 708 (2013) 19-23.

[22] D. Emin, T. L. Aselage, A proposed boron-carbide-based solid-state neutron detector, J. Appl. Phys. 97 (2005) 013529.

[23] A. N. Caruso, The physics of solid-state neutron detector materials and geometries, J. Phys. Condens. Matter. 22 (2010) 1-32.

[24] M. Sky Driver, M. M. Paquette, S. Karki, B. J. Nordell, and A. N. Caruso, The electronic and chemical structure of the $\mathrm{a}-\mathrm{B}_{3} \mathrm{CO}_{0.5}: \mathrm{H}_{y}$-to-metal interface from photoemission spectroscopy: implications for Schottky barrier heights, J. Phys.: Condens. Matter 24 (2012) 445001.

[25] S. W. King, M. French, G. Xu, B. French, M. Jaehnig, J. Bielefeld, J. Brockman, M. Kuhn, Valence band offset and Schottky barrier at amorphous boron and boron carbide interfaces with silicon and copper, Appl. Surf. Sci. 285P (2013) 545. 
[26] S. W. King, M. French, J. Bielefeld, M. Jaehnig, M. Kuhn, and B. French, X-ray Photoelectron Spectroscopy Investigation of the Schottky Barrier at a-BN:H/Cu Interfaces, Electrochem. Solid-State Lett. 14 (2011) H478.

[27] R. James, F. L. Pasquale, J. A. Kelber, Plasma-enhanced chemical vapor deposition of ortho -carborane: structural insights and interaction with $\mathrm{Cu}$ overlayers, J. Phys. Condens. Matter. 25 (2013) 355004.

[28] R. F. Pierret, 1996 Semiconductor Device Fundamentals, 2nd ed. (Reading, MA: Addison Wesley)

[29] S. Dimitrijev, 2006 Principles of semiconductor devices (New York: Oxford University Press)

[30] A.N. Caruso, S. Balaz, B. Xu, P.A. Dowben, A.S. McMullen-Gunn, J. I. Brand, Y. B. Losovyj, D. N. McIlroy, Surface photovoltage effects on the isomeric semiconductors of boroncarbide, Appl. Phys. Lett. 84 (2004) 1302.

[31] W. M. H. Sachtler, G. J. H. Dorgelo, A. A. Holscher, The work function of gold, Surf. Sci. 5 (1966) 221.

[32] H. C. Potter and J. M. Blakeley, LEED, Auger spectroscopy, and contact potential studies of copper-gold alloy single-crystal surfaces, J. Vac. Sci. Technol. 12 (1975) 635.

[33] P.E.C. Franken, V. Ponec, Ethylene adsorption on thin films of Ni, Pd, Pt, $\mathrm{Cu}, \mathrm{Au}$ and $\mathrm{Al}$; Work function measurements, Surf. Sci. 53 (1975) 341.

[34] B. E. Nieuwenhuys, W. H. M. Sachtler, Crystal face specificity of nitrogen adsorption on a platium field emission tip, Surf. Sci. 34 (1973) 317.

[35] N. Fairly, CasaXPS: Processing Software for XPS, AES, SIMS and More, http://www.casaxps.com/

[36] János Végh, The Shirley background revised, J. Electron Spectrosc. Relat. Phenom. 151 (2006) 159.

[37] E. Echeverria, B. Dong, G. Peterson, J. P. Silva, E. R. Wilson, M. S. Driver, Y-S. Jun, G. D. Stucky, S. Knight, T. Hoffman, Z.-Kang Han, N. Shao, Y. Gao, W.-N. Mei, M. Nastasi, P. A. Dowben, J. A. Kelber, Semiconducting Boron Carbides with Better Charge Extraction through the addition of Pyridine Moieties, J. Phys. D. Appl. Phys. (2016), in press

[38] R. Bao, Z. Yan, and D. B. Chrisey, Charge carrier lifetime in boron carbide thin films, Appl. Phys. Lett. 98 (2011) 192106.

[39] M. K. Kolel-Veetil, R. M. Gamache, N. Bernstein, R. Goswami, S. B. Qadri, K. P. Fears, J. B. Miller, E. R. Glaser and T. M. Keller, Substitution of silicon within the rhombohedral boron 
carbide $\left(\mathrm{B}_{4} \mathrm{C}\right)$ crystal lattice through high-energy ball-milling, J. Mater. Chem. C, 3 (2015) 11705 .

[40] F. L. Pasquale, J. Liu, P. A. Dowben and J. A. Kelber, Novel semiconducting alloy polymers formed from ortho-carborane and 1,4-diaminobenzene, Mater. Chem. Phys. 133 (2012) 901.

[41] J. Zheng, L. Wang, K. Katsiev, Y. Losovyj, E. Vescovo, D. Wayne Goodman, P. A. Dowben, J. Lu, and W.-N. Mei, Adsorption configurations of carbon monoxide on gold monolayer supported by graphene or monolayer hexagonal boron nitride: a first-principles study, Eur. Phys. J. B. 86 (2013) 441.

[42] G. Giovannetti, P.A. Khomyakov, G. Brocks, V.M. Karpan, J. van den Brink, and P. J. Kelly, Doping graphene with metal contacts, Phys. Rev. Lett. 101, 026803 (2008) 026803.

[43] P. A. Khomyakov, G. Giovannetti, P. C. Rusu, G. Brocks, J. van den Brink, and P. J. Kelly, principles study of the interaction and charge transfer between graphene and metals, Phys. Rev. B. 79, 195425 (2009) 195425.

[44] K. Katsiev, Y. Losovyj, Lu Wang, W.-N. Mei, J. Zheng, E. Vescovo, L. Lu, P.A. Dowben, and D. W. Goodman, The band structure of carbon monoxide on 2-D Au islands on graphene, Appl. Surf. Sci. 304 (2014) 35. 


\section{Table Caption}

Table 1. Summary of the X-ray photoemission derived boron and carbon components, the B 1s and $\mathrm{C} 1 \mathrm{~s}$ core levels respectively, as a function of the addition (deposition) and removal ( $\mathrm{Ar}^{+}$ bombardment or sputtering) of a gold overlayer.

\section{Figures Caption}

Figure 1. Evolution of the XPS core level spectra of the $\mathrm{B}(1 \mathrm{~s})$ (left), and $\mathrm{C}(1 \mathrm{~s})$ (right) as a function of $\mathrm{Au}$ exposure; $\mathbf{a}$ and e cleaned sample, $\mathbf{b}$ and $\mathbf{f}$ first $\mathrm{Au}$ deposition, $\mathbf{c}$ and $\mathbf{g}$ last $\mathrm{Au}$ deposition, and $\mathbf{d}$ and $\mathbf{h}$ after 2 hours and 45 min sputtering.

Figure 2. Shift in the binding energy of the $\mathrm{B}(1 \mathrm{~s})$ peak with increasing Au overlayer thickness deposition (black stars), and after $\mathrm{Ar}^{+}$bombardment to remove the gold overlayer (red triangles $4)$.

Figure 3. (a) Current versus voltage of the n-type boron carbide film on p-type Silicon (m$\mathrm{B}_{10} \mathrm{C}_{2} \mathrm{H}_{\mathrm{x}} / \mathrm{Si}$ ), and (b) Capacitance versus voltage as a function of frequency (blue $10 \mathrm{MHz}$, red 10 $\mathrm{kHz}$, and black $1 \mathrm{kHz}$ ). Inset in (b) shows an expanded scale plot for the for $10 \mathrm{MHz}$ capacitance data.

Figure 4. A model of diffusion capacitance, $C D$, overlaid on $C(V)$ data at $10 \mathrm{kHz}$. The calculated $C_{D}$ indicates an effective carrier lifetime of about $50 \mathrm{~ns}$. 


\section{Table}

\begin{tabular}{|l|c|c|c|c|c|c|c|c|}
\cline { 2 - 9 } \multicolumn{1}{c|}{} & \multicolumn{2}{|c|}{$\mathbf{B}(\mathbf{1 s}) \mathbf{B}-\mathbf{B}$ bond } & \multicolumn{2}{c|}{$\mathbf{B}(\mathbf{1 s}) \mathbf{B}-\mathbf{C}$ bond } & \multicolumn{2}{c|}{$\mathbf{C}(\mathbf{1 s}) \mathbf{C}-\mathbf{B}$ bond } & \multicolumn{2}{c|}{$\begin{array}{c}\mathbf{C}(\mathbf{s}) \mathbf{C}-\mathbf{A u} \\
\text { bond }\end{array}$} \\
\cline { 2 - 10 } & $\begin{array}{c}\mathbf{B E} \\
(\mathbf{e V})\end{array}$ & $\begin{array}{c}\text { atomic } \\
\mathbf{\%} \mathbf{B}\end{array}$ & $\begin{array}{c}\mathbf{B E} \\
(\mathbf{e V})\end{array}$ & $\begin{array}{c}\text { atomic } \\
\mathbf{\%} \mathbf{B}\end{array}$ & $\begin{array}{c}\mathbf{B E} \\
(\mathbf{e V})\end{array}$ & $\begin{array}{c}\text { atomic } \\
\mathbf{\%} \mathbf{C}\end{array}$ & $\begin{array}{c}\mathbf{B E} \\
(\mathbf{e V})\end{array}$ & $\begin{array}{c}\text { atomic } \\
\mathbf{\%} \mathbf{C}\end{array}$ \\
\hline Clean Sample & 188.3 & 45 & 189.2 & 55 & 283.6 & 100 & - & - \\
\hline 1st Au deposition & 188.7 & 80 & 191.5 & 20 & 284.6 & 95 & 289.3 & 5 \\
\hline 2nd Au deposition & 188.8 & 83 & 191.9 & 17 & 284.8 & 95 & 288.7 & 5 \\
\hline 3rd Au deposition & 188.8 & 77 & 192.1 & 23 & 284.8 & 87 & 288.3 & 13 \\
\hline 1st sputtering (15 min) & 188.7 & 89 & 191.0 & 11 & 283.3 & 74 & 285.1 & 26 \\
\hline 2nd sputtering (30 min & 188.6 & 81 & 189.8 & 19 & 283.4 & 100 & - & - \\
\hline 3rd sputtering (30 min) & 188.4 & 58 & 189.3 & 42 & 283.4 & 100 & - & - \\
\hline 4th sputtering (1 hour) & 188.3 & 45 & 189.2 & 55 & 283.5 & 100 & - & - \\
\hline
\end{tabular}

Table 1 
Figures

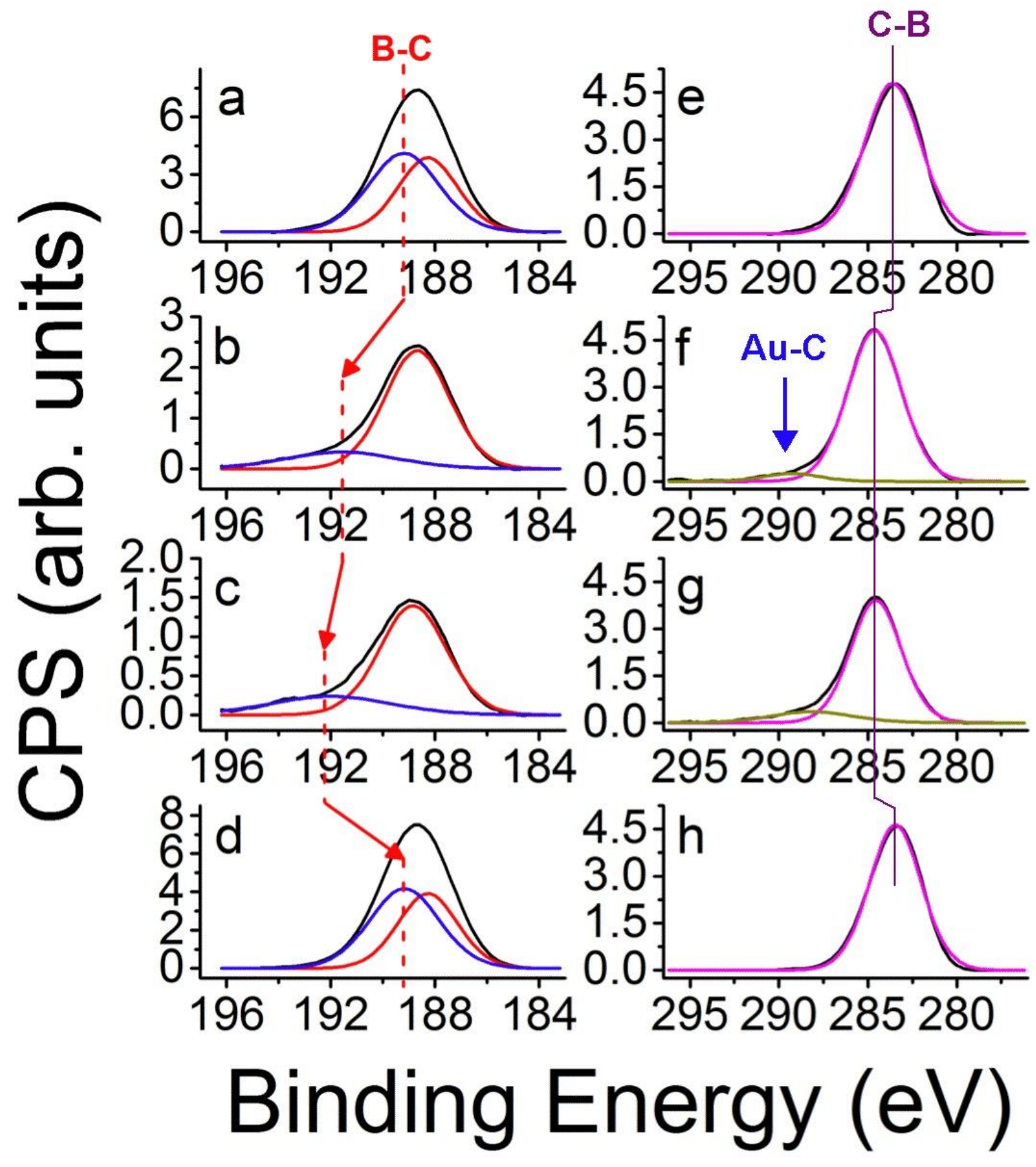

Figure 1 


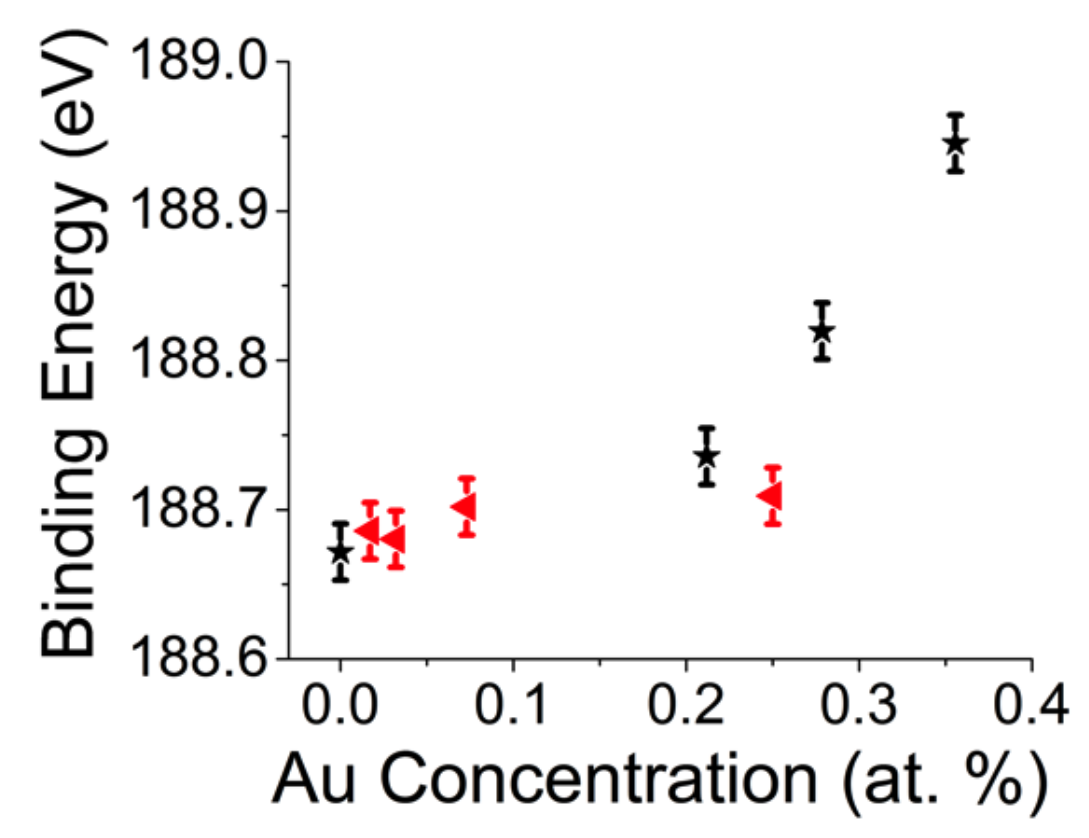

Figure 2 

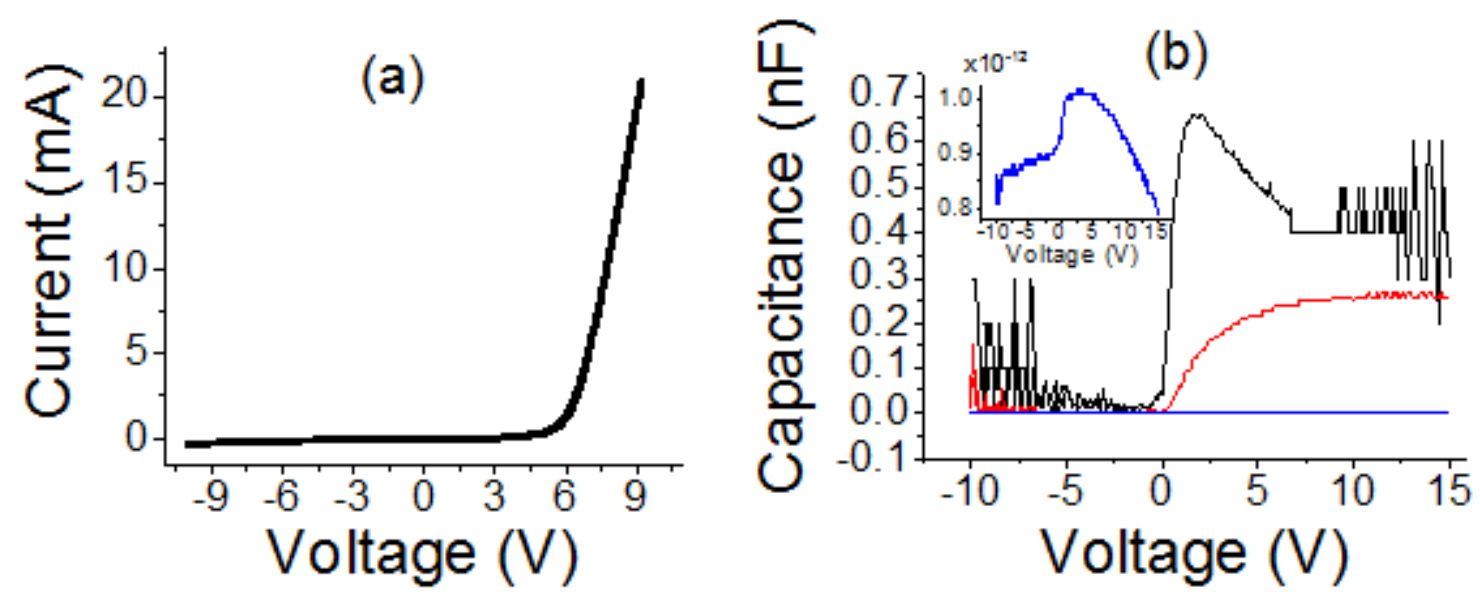

Figure 3 


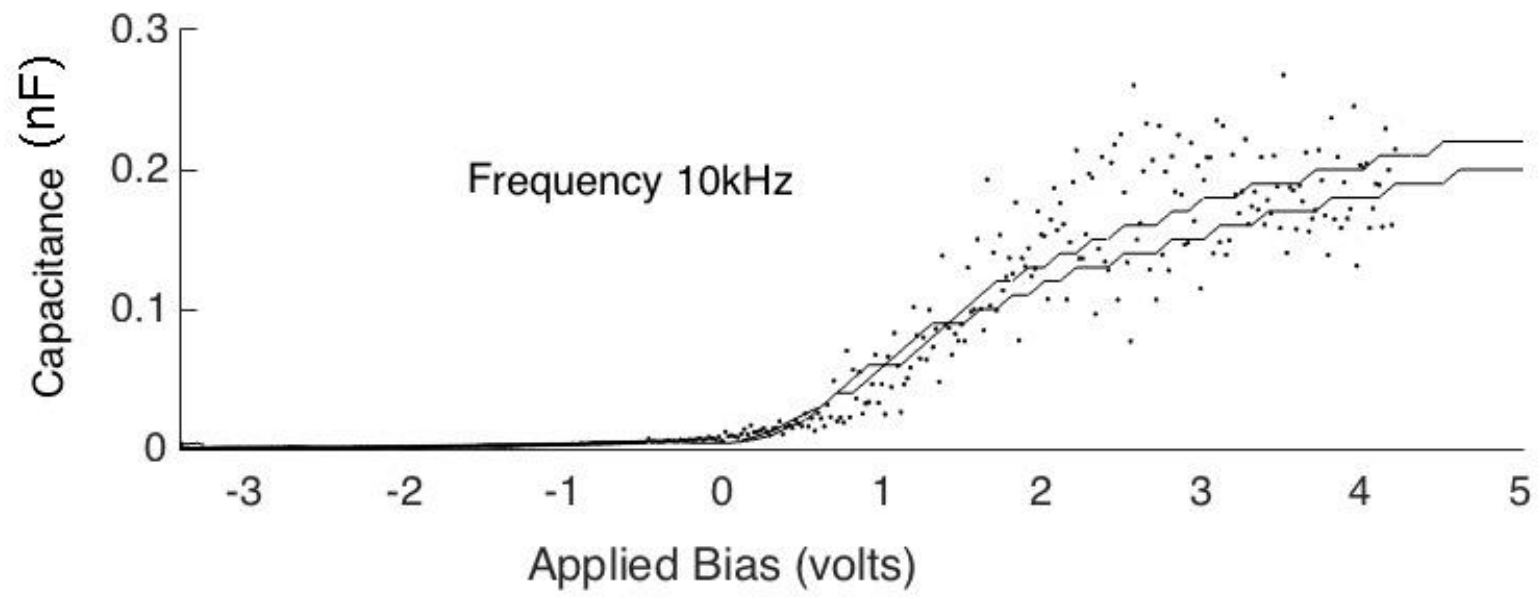

Figure 4 